\begin{tabular}{|l|c|c|c|}
\hline & HR & $95 \% \mathrm{CI}$ & $p$ \\
\hline Age, $y$ & 0,9336 & 0,8947 to 0,9742 & 0,0016 \\
\hline Disease duration, $y$ & 0,9712 & 0,9257 to 1,0191 & 0,2340 \\
\hline SLEDAI & 1,1193 & 0,8084 to 1,5498 & 0,4971 \\
\hline SLICC & 1,5583 & 0,7785 to 3,1191 & 0,2102 \\
\hline [HCQm] ng mI & 0,9997 & 0,9987 to 1,0007 & 0,5983 \\
\hline [DCQ] ng'mI & 0,9973 & 0,9922 to 1,0024 & 0,3048 \\
\hline $\begin{array}{l}\text { Clinical remission } \\
\text { off on therapy }\end{array}$ & 1,3702 & 0,6001 to 3,1282 & 0,4546 \\
\hline $\begin{array}{l}\text { Complete remission } \\
\text { off on therapy }\end{array}$ & 0,7298 & 0,3197 to 1,6663 & 0,4546 \\
\hline Time remission & 0,7984 & 0,6287 to 1,0138 & 0,0647 \\
\hline $\begin{array}{l}\text { Previous renal } \\
\text { ivvolvement }\end{array}$ & 1,1207 & 0,4942 to 2,5416 & 0,7850 \\
\hline Time HCQ & 0,9735 & 0,9128 to 1,0383 & 0,4140 \\
\hline Glucocorticoids & 2,1489 & 0,8966 to 5,1502 & 0,0563 \\
\hline $\begin{array}{l}\text { Immumosuppressive } \\
\text { therapy }\end{array}$ & 3,6639 & 1,5924 to 8,4304 & 0,0023 \\
\hline HCQ dosage & 0,4995 & 0,2113 to 1,1805 & 0,1137 \\
\hline
\end{tabular}

Figure 1. Predictors of flares analyzed by Cox regression.*Serena Fasano and Valentina Messiniti contributed equally to this abstract

Disclosure of Interests: None declared

DOI: 10.1136/annrheumdis-2021-eular.192

\section{AB0280 1 THE INFLUENCE OF TARGET THERAPY AS WELL AS GLUCOCORTICOIDS TAPERING ON DISEASE FLARE IN SYSTEMIC LUPUS ERYTHEMATOSUS: RESULTS FROM A PROSPECTIVE CHINESE COHORT}

Y. Hao $^{1}$, L. Ji ${ }^{1}$, D. Gao ${ }^{2}$, Y. Fan ${ }^{1}$, B. Wei ${ }^{1}$, Y. Geng ${ }^{1}$, X. Zhang ${ }^{1}$, G. Li ${ }^{1}$, Z. Zhang ${ }^{1}$ ${ }^{1}$ Peking University First Hospital, Department of Rheumatology and Clinical Immunology, Beijing, China; ${ }^{2}$ Peking University First Hospital, Department of Rheumatology and Clinical Immunology, Beijing,

Background: Treat-to-target in systemic lupus erythematosus (SLE) has been proposed for 7 years and several recommendations were developed [1]. In these recommendations, prevention of flares should be a realistic target. Meanwhile, 'remission' or 'low disease activity' was recommended as the treatment target and minimizing glucocorticoids (GC) dose or withdrawal if possible was suggested in the maintenance treatment. However, would target therapy and GC tapering/withdrawal influence disease flare?

Objectives: To investigate the frequency and determinants of disease flare, especially the influence of target therapy as well as GC tapering on flare in Chinese lupus patients.

Methods: The baseline and follow-up data of all consecutive patients in a prospective longitudinal lupus cohort from January 2017 to June 2020 were collected. The lupus low disease activity state (LLDAS) was defined as in Golder et al., 2019[2]. The criteria for remission were from DORIS definitions [3]. Flare was assessed using the SELENA-SLEDAl flare index [4].

Results: We enrolled 185 patients with disease duration at recruitment of 2.3 (0.8-7.7) years. During the $26.2(12.5-34.5)$ months of follow-up, $73(39.5 \%)$ patients experienced 95 flares, including $70 \mathrm{mild} /$ moderate and 25 severe flares. The incidence of flare per patient-year was 0.27 . Kaplan-Meier analyses showed that compared with those who never achieved LLDAS or DORIS, the patients who achieved the target at least once had a higher flare free survival rate; meanwhile, the patients with prednisone withdrawn had significantly lower flare free rate compared with those with small dose of GC maintained $(\leq 7.5 \mathrm{mg} / \mathrm{d})$ (Figure $1 \mathrm{~A}$ ), but among the patients with different prednisone maintain doses (7.5 5mg, $5 \sim 2.5 \mathrm{mg}$, and $\leq 2.5 \mathrm{mg}$ ) there was not significant difference (Figure 1B). Cox regression analysis showed that younger age at disease onset and lower Complement 3 (C3) level at recruitment were independent risk factors for flare and achieving LLDAS or DORIS $\geq 50 \%$ of visits was independent protective factor (Table 1)

Conclusion: In this Chinese prospective SLE cohort, age at disease onset, C3 level at recruitment and therapeutic target achieving influenced disease flare independently and significantly. GC tapering in appropriate patients and with appropriate pace did not increase the flare rate, but prednisone withdrawal may induce more disease exacerbation, which needs to be confirmed by large prospective studies.

\section{REFERENCES:}

[1] Van Vollenhoven R F, et al. Treat-to-target in systemic lupus erythematosus: recommendations from an international task force. Ann Rheum Dis, 2014 73(6): 958-967

[2] Golder, V., et al. Lupus low disease activity state as a treatment endpoint for systemic lupus erythematosus: a prospective validation study. The Lance Rheumatology, 2019. 1(2): p. e95-e102.

[3] van Vollenhoven R, et al. A framework for remission in SLE: consensus findings from a large international task force on definitions of remission in SLE (DORIS). Ann Rheum Dis. 2017. 76(3): 554-561.

[4] Petri M, et al. Classification and definition of major flares in SLE clinical trials Lupus. 1999. 8(8): 685-691.

Table 1. Determinants of disease flare by multivariate Cox regression analyses

\begin{tabular}{|c|c|c|c|c|c|c|c|c|c|}
\hline & \multicolumn{3}{|c|}{$\begin{array}{c}\text { Model } 1 \\
{(\text { LLDAS })^{\Delta}}^{\Delta}\end{array}$} & \multicolumn{3}{|c|}{$\begin{array}{c}\text { Model } 2 \\
\left(\text { RONT) }{ }^{\Delta}\right.\end{array}$} & \multicolumn{3}{|c|}{$\begin{array}{c}\text { Model 3 } \\
(\text { Complete RONT })^{\Delta}\end{array}$} \\
\hline & $\mathrm{HR}$ & $95 \% \mathrm{Cl}$ & $\begin{array}{c}\mathrm{P} \\
\text { value }\end{array}$ & $\mathrm{HR}$ & $95 \% \mathrm{Cl}$ & $\begin{array}{c}\mathrm{P} \\
\text { value }\end{array}$ & $\mathrm{HR}$ & $95 \% \mathrm{Cl}$ & $\begin{array}{c}\mathrm{P} \\
\text { value }\end{array}$ \\
\hline $\begin{array}{l}\text { Age at disease } \\
\text { onset (years) }^{\dagger}\end{array}$ & 0.97 & $0.95-0.99$ & 0.004 & 0.97 & $0.95-0.99$ & 0.003 & 0.97 & $0.95-0.99$ & 0.003 \\
\hline $\begin{array}{l}\text { Anti-dsDNA } \\
\text { positive at } \\
\text { recruitment }\end{array}$ & 1.34 & $0.82-2.18$ & 0.217 & 1.12 & $0.68-1.85$ & 0.649 & 1.19 & $0.73-1.96$ & 0.486 \\
\hline $\begin{array}{l}\mathrm{C} 3(\mathrm{mg} / \mathrm{L}) \text { at } \\
\text { recruitment }\end{array}$ & 0.998 & $\begin{array}{l}0.997- \\
0.999\end{array}$ & 0.004 & 0.998 & $\begin{array}{l}0.997- \\
0.999\end{array}$ & 0.007 & 0.998 & $\begin{array}{l}0.997- \\
1.000\end{array}$ & 0.010 \\
\hline $\begin{array}{l}\text { Minimum pred- } \\
\text { nisone dose } \\
\text { during follow- } \\
\text { up }(\mathrm{mg} / \mathrm{d})\end{array}$ & 0.98 & $0.90-1.08$ & 0.716 & 1.01 & $0.94-1.08$ & 0.747 & 1.04 & $0.97-1.11$ & 0.243 \\
\hline $\begin{array}{l}\text { Therapeutic target } \\
\text { achieved } \geq 50 \% \\
\text { of observa- } \\
\text { tions }{ }^{\Delta}\end{array}$ & 0.60 & $0.39-0.94$ & 0.001 & 0.54 & $0.34-0.87$ & 0.011 & 0.68 & $0.51-0.92$ & 0.011 \\
\hline
\end{tabular}

$\Delta$ In the three hazard models, the different target achievement status were included respectively.RONT: Clinical remission on treatment; Complete RONT: Complete remission on treatment.

Disclosure of Interests: None declared

DOI: 10.1136/annrheumdis-2021-eular.623

\section{AB0281 MORTALITY PREDICTORS IN PATIENTS WITH SYSTEMIC LUPUS ERYTHEMATOSUS: A SINGLE TERTIARY CENTER REFERRAL EXPERIENCE}

C. M. Gamboa-Alonso ${ }^{1}$, G. Figueroa-Parra' ${ }^{1}$, A. L. De-Leon-Ibarra ${ }^{1},{ }^{1}$ M. Á. Villarreal-Alarcón ${ }^{1}$, J. Díaz-Angulo ${ }^{1}$, D. Vega-Morales ${ }^{1}$, D. Á. GalarzaDelgado'. ' Universidad Autónoma de Nuevo León, Reumatología e Inmunología Clínica, Monterrey, Mexico

Background: Systemic Lupus Erythematosus (SLE) is a heterogeneous chronic multisystemic disease that has an increased risk of requiring inpatient management with higher morbidity and mortality rates.

The most frequent causes of mortality are a high disease activity, infections, and cardiovascular diseases.

Objectives: To determine the predictors of mortality in patients diagnosed with SLE.

Methods: A longitudinal, descriptive, observational study was performed from March 2017-March 2020 at the University Hospital of the Autonomous University of Nuevo León, México, including patients with a diagnosis of SLE according to the ACR-EULAR 2012/2019 criteria.

Descriptive statistics were used for demographic variables. Associations between mortality and clinical variables were determined using binary logistic regression analysis; a $p<0.05$ was considered statistically significant. The SPSS program version 20 was used.

Results: One-hundred and eighty-six patients with SLE diagnosis who fulfilled ACR-EULAR 2012/2019 criteria were included, 161 (86.6\%) were women; the mean age was 35.8 (SD 15.41) years. The main chief complaints were dyspnea $31(16.7 \%)$, fever in $28(15.1 \%)$, renal involvement in $21(11.29 \%)$, and arthritis in $19(10.22 \%)$ patients.

Of the 186 patients, $34(18.3 \%)$ had a readmission, $13(7 \%)$ required intensive care unit management, $68(36.6 \%)$ had some type of infection and $22(11.8 \%)$ died. Factors associated with mortality are shown in table 1.

Patients receiving steroids and immunosuppression previous to hospitalization were $73(39.2 \%)$ and $92(49.5 \%)$ respectively.

Conclusion: Infections remain the leading cause of death in SLE patients. Factors that predispose to infections are a chronic use of steroids and immunosuppression as well as high activity of disease. 


\section{REFERENCES:}

[1] Wu X-Y, Yang M, Xie Y-S, Xiao W-G, Lin J, Zhou B, et al. Causes of death in hospitalized patients with systemic lupus erythematosus: a 10-year multicenter nationwide Chinese cohort. Clin Rheumatol. enero de 2019;38(1):107-15

Table 1. Association between clinical and therapeutic factors with mortality in SLE patients.

\begin{tabular}{lcc}
\hline Factors associated with mortality & Univariado & Multivariado \\
\hline & $\beta(95 \%$ IC) & $\beta(95 \%$ IC) $\square$ \\
\hline Age & $0.93(0.96-1.02)$ & $0.98(0.96-1.02)$ \\
Use of mechanical ventilation & $3.83(1.07-13.4)^{\star}$ & $3.07(0.59-16.04)$ \\
Previous use of steroids & $3.92(1.51-10.15)^{\star}$ & $2.04(0.58-7.35)$ \\
Previous use of immunosupression & $4.04(1.42-11.45)^{\star}$ & $2.85(0.71-11.48)$ \\
Infection & $3.57(1.41-9.01)^{\star}$ & $3.25(1.19-8.86)^{\star}$
\end{tabular}

$\mathrm{p}<0.05$ *

Disclosure of Interests: None declared

DOI: 10.1136/annrheumdis-2021-eular.941

\section{AB0282 SAFETY,TOLERABILITY AND SELECTIVE EXPANSION OF REGULATORY T CELLS BY A SINGLE DOSE OF THE NOVEL IL-2 MUTEIN PT101 IN A PHASE 1 STUDY IN HEALTHY VOLUNTEERS}

J. S. Sundy ${ }^{1}$, K. L. Otipobyy ${ }^{1}$, N. Higginson-Scott ${ }^{1}$, J. Visweswaraiah ${ }^{1}$, E. Sampson ${ }^{1}$, K. Kis-Toth ${ }^{1}$, A. Monsef ${ }^{1}$, P. Petaipimol ${ }^{1}$, D. Essayan², M. E. Cosenza ${ }^{3}$, R. Kakkar ${ }^{1}$, J. Viney ${ }^{1} .{ }^{1}$ Pandion Therapeutics, Watertown, MA, United States of America; ${ }^{2}$ Oncord, Inc, West Lake Village, CA, United States of America; ${ }^{3}$ MEC Regulatory Consulting, LLC, Moorpark, CA, United States of America

Background: Activation and expansion of regulatory T cells (Tregs) has been proposed as a strategy to treat autoimmunity. When administered in low doses, IL-2 expands and activates Tregs leading to clinical response in several autoimmune diseases. However, the narrow therapeutic window of IL-2 results in loss of selectivity for Tregs and concurrent activation of conventional T cells (Tconv) and NK cells, limiting its clinical utility. This loss of selectivity may negate the clinical benefit of Treg activation and lead to dose-limiting side effects. PT101 is a novel engineered variant of IL-2 fused to an Fc protein backbone which in preclinical studies selectively activates Tregs without expanding Tconv or NK cells. PT101 is in clinical development for the treatment of patients with autoimmune diseases. Objectives: To assess the safety, tolerability, pharmacokinetics (PK) and pharmacodynamics (PD) of PT101 after a single dose in healthy human volunteers. Methods: We conducted a randomized, double-blind, single-ascending dose trial of PT101 or placebo (3:1 allocation). Five dose levels from $1 \mathrm{mg}$ to $10 \mathrm{mg}$ were administered by subcutaneous injection. Adverse events, physical examination findings, and clinical laboratory results were assessed for 29 days. Serum PT101 levels and antidrug antibody were assessed. Changes in mononuclear cell populations were measured in peripheral blood by flow cytometry.

Results: 56 subjects were administered PT101 or placebo. All subjects completed the study. There were no deaths, serious adverse events, dose limiting toxicities, or clinically significant changes in vital sign, ECG, or laboratory results. All adverse events were Grade 1 or 2 and self-limited. Injection site reactions were the most common adverse event. Transient increases in eosinophil counts were observed in some subjects, consistent with the known class effect of IL-2. Peak levels of PT101 occurred 11.0 to 14.6 hours after administration, and declined with a mean half-life of 20.4 to 28.3 hours, demonstrating linear exposure through the dose range. No anti-drug antibodies were induced. PT101 caused dose-related expansion of Tregs that plateaued at doses between 3.5 and $10 \mathrm{mg}$. Mean maximum expansion above baseline was 3.6-fold for total Tregs and 72.5 -fold for the CD25bright subset of Tregs. Maximal expansion was observed by Day 8-10 with a return toward baseline by Day 29 . Over $80 \%$ of subjects achieved a 2 -fold or greater expansion of total Tregs (Table 1). No significant expansion of Tconv or NK cells was observed at any dose level.

Table 1. Percent Total Treg Responders

\begin{tabular}{lcccccc}
\hline & Placebo & $1 \mathrm{mg}$ & $3.5 \mathrm{mg}$ & $5 \mathrm{mg}$ & $7.5 \mathrm{mg}$ & $10 \mathrm{mg}$ \\
Fold Change Total Tregs & $(\mathrm{n}=14)$ & $(\mathrm{n}=6)$ & $(\mathrm{n}=12)$ & $(\mathrm{n}=12)$ & $(\mathrm{n}=6)$ & $(\mathrm{n}=6)$ \\
\hline$\geq 2 \mathrm{X}$ & $7 \%$ & $33 \%$ & $83 \%$ & $83 \%$ & $100 \%$ & $100 \%$ \\
$\geq 3 \mathrm{X}$ & $0 \%$ & $0 \%$ & $58 \%$ & $75 \%$ & $33 \%$ & $50 \%$ \\
$\geq 4 \mathrm{~N}$ & $0 \%$ & $0 \%$ & $24 \%$ & $42 \%$ & $33 \%$ & $17 \%$ \\
\hline
\end{tabular}

Conclusion: PT101 was safe and well tolerated after a single dose in healthy volunteers. Marked expansion of both total Treg and CD25bright Treg cells was observed. High selectivity for Tregs was observed with no significant expansion of pro-inflammatory Tconv and NK cells even at the highest dose studied. These results support the therapeutic potential of PT101 in planned multiple dose studies in systemic lupus erythematosus, ulcerative colitis, and other autoimmune diseases.

\section{REFERENCES:}

[1] Klatzmann, D., Abbas, A. The promise of low-dose interleukin-2 therapy for autoimmune and inflammatory diseases. Nat Rev Immunol 15, 283-294 (2015)

Acknowledgements: Pandion Therapeutics acknowledges the participants and research staff who contributed to this clinical trial

Disclosure of Interests: John S Sundy Shareholder of: Pandion Therapeutics, Employee of: Pandion Therapeutics, Kevin L. Otipoby Shareholder of: Pandion Therapeutics, Employee of: Pandion Therapeutics, Nathan Higginson-Scott Shareholder of: Pandion Therapeutics, Employee of: Pandion Therapeutics, Jyothsna Visweswaraiah Shareholder of: Pandion Therapeutics, Employee of: Pandion Therapeutics, Erik Sampson Shareholder of: Pandion Therapeutics, Employee of: Pandion Therapeutics, Katalin Kis-Toth Shareholder of: Pandion Therapeutics, Employee of: Pandion Therapeutics, Adrianne Monsef Shareholder of: Pandion Therapeutics, Employee of: Pandion Therapeutics, Parika Petaipimol Shareholder of: Pandion Therapeutics, Employee of: Pandion Therapeutics, David Essayan Consultant of: Pandion Therapeutics, Mary Ellen Cosenza Consultant of: Pandion Therapeutics, Rahul Kakkar Shareholder of: Pandion Therapeutics, Employee of: Pandion Therapeutics, Jo Viney Shareholder of: Pandion Therapeutics, Employee of: Pandion Therapeutics DOI: 10.1136/annrheumdis-2021-eular.1200

\section{AB0283 CHOREOATHETHOSIS AND LONGITUDINALLY EXTENSIVE TRANSVERSE MYELITIS AS RARE AND SEVERE MANIFESTATIONS OF NEUROPSYCHIATRIC SYSTEMIC LUPUS ERYTHEMATOSUS AND PRIMARY SJÖGREN'S SYNDROME - A TWO-CENTER EXPERIENCE}

P. Korsten ${ }^{1}$, M. Plüß ${ }^{1}$, S. Glaubitz ${ }^{2}$, A. Jambus ${ }^{3}$, R. Vasko ${ }^{1}$, B. M. Göricke ${ }^{2}$, S. Piantoni ${ }^{4} .{ }^{1}$ Universitätsmedizin Göttingen, Department of Nephrology and Rheumatology, Göttingen, Germany; ${ }^{2}$ Universitätsmedizin Göttingen, Department of Neurology, Göttingen, Germany; ${ }^{3}$ Universitätsmedizin Göttingen, Department of Neuroradiology, Göttingen, Germany; ${ }^{4}$ University of Brescia, Department of Rheumatology and Clinical Immunology, Brescia, Italy

Background: Systemic lupus erythematosus (SLE) can affect almost any organ system. Nevertheless, Lupus nephritis and neuropsychiatric manifestations (NPSLE) are associated with increased mortality (1). Therapeutic options include glucocorticoids, often pulse methylprednisolone (MP), and other immunosuppressive therapies. In refractory cases, therapeutic plasma exchange, rituximab, or intravenous immunoglobulins are often used (2). However, an optimal therapeutic strategy has not been established because NPSLE is an exclusion criterion in most clinical trials. In addition, NPSLE can present with a broad spectrum of manifestations ranging from cognitive dysfunction to severe and life-threatening disease with choreoathetosis or transverse myelitis (TM). In primary Sjögren's syndrome (pSS), neurological manifestations most often include peripheral neuropathies, but TM has also been reported.

Objectives: To analyze the clinical presentation and outcomes after treatment in severe, life-threatening NPSLE.

Methods: We retrospectively analyzed clinical, laboratory, and imaging features in severe NPSLE manifestations in SLE and pSS patients at two tertiary academic centers (University Medical Center Göttingen, Germany, and ASST Spedali Civili Brescia, Italy) with a high volume of SLE patients. Severe NPSLE was defined as either severe movement disorder or extensive tetra- or paraplegia secondary to (longitudinally extensive) transverse myelitis.

Results: Our retrospective chart review resulted in seven patients fulfilling the inclusion criteria (six with SLE and 1 with pSS). Of these, five were females $(71.4 \%)$ Median age was 26 (16-55) years. Three were of Asian origin, four were of European descent. Median disease duration was 15 (2-228) months. Three patients presented with severe choreoathetosis, all had positive ANA, anti-dsDNA antibodies (abs), and complement consumption. Of note, all three had at least one positive antiphospholipid antibody (APLA). All patients received IV MP $1 \mathrm{~g} \times 3$ and mycophenolate mofetil and achieved complete remission. Of the four patients with longitudinally extensive TM, all were ANA positive, only two had anti-dsDNA abs. None of them had APLA, and only one tested positive for anti-aquaporine-4 abs. Of all patients, only one had positive ribosomal P-abs. Patients with TM received IV MP $1 \mathrm{~g} \times 5$ and either RTX (4 cycles with $375 \mathrm{mg} / \mathrm{m}^{2}$ or IVlg $0.4 \mathrm{~g} / \mathrm{kg} / \mathrm{d} \times 5$ ). All four TM patients improved; two improved markedly, two only moderately with residual deficits as assessed by EDMUS-grading scale and functional independence measure. Conclusion: Severe NPSLE, defined as choreoathetosis or TM require intensive treatment. While the former patients achieved complete remission, two of four patients with TM only achieved partial remission. Our data support the use of early 